Original Article

\title{
Analysis of walker-aided walking by the healthy elderly with a walker pocket of different weights attached at different locations
}

\author{
Eunj Shin, OT ${ }^{1)}$, Byongun Jeon, PhD, OT²), Bokyung Song, PhD, OT²), Minho Baek, PhD ${ }^{3)}$, \\ Hyolyun Roh, PhD, $\left.\mathrm{PT}^{4}\right)^{*}$ \\ 1) Graduate School, Major in Occupational Therapy, Kangwon National University, Republic of Korea \\ 2) Department of Occupational Therapy, Kangwon National University, Republic of Korea \\ 3) Department of Fire \& Disaster Prevention, Major in Emergency Management, Kangwon National \\ University, Republic of Korea \\ 4) Department of Physical Therapy, Kangwon National University: Hwangio-ri, Samcheok-si, \\ Gangwon-do 240-907, Republic of Korea
}

\begin{abstract}
Purpose] This study aims to provide information on safe walker-aided walking by analyzing elderly subjects' walking with a walker pocket of different weights attached at different locations. [Subjects and Methods] Twenty elderly right-handed males participated in the study, and a walking analyzer was used to examine their walking with a pocket attached to the left, center, and right side of the walker. The weight of the pocket was set at three levels relative to the average weight of the subject group: $0 \%$ (without pocket), $2.5 \%(2 \mathrm{~kg})$, and $5.5 \%(4 \mathrm{~kg})$. [Results] In terms of the pocket location, step width was the narrowest when the pocket was attached to the right side, while the other elements of walking did not change. In terms of the pocket weight, all elements of walking showed changes. A heavier pocket led to a shorter step length and stride, a greater step width, and longer time. [Conclusion] When elderly people use a pocket-attached walker, the pocket is recommended to be attached to the right side of the walker, and its weight should be kept under 5.5\% of the user's weight to ensure safe walking. Key words: Elderly, Walker-aided walking, Walker pocket
\end{abstract}

(This article was submitted Jul. 1, 2015, and was accepted Jul. 31, 2015)

\section{INTRODUCTION}

Canes and walkers provide support and balance, and they can help some people avoid falls ${ }^{1)}$. Therefore, the use of personal assistance mobility devices is strongly recommended to keep the elderly independent ${ }^{2}$. As a walker requires both of a user's hands to control, a separate walker pocket becomes necessary to contain the user's personal belongings ${ }^{3)}$. Some walkers are simple, whereas others are enhanced to have wheels or even a basket to help carry items. A walker pocket should not obstruct the operation of the walker, and it should be designed in a way that prevents the walker from falling down when the pocket is loaded to the maximum capacity. However, accidents related to safety and caused by elderly-friendly devices frequently occur, with half of the accidents involving falls ${ }^{3)}$. A walker has four supporting points and a wide base that makes it relatively stable. However, when an external load is applied, the user's walk-

*Corresponding author. Hyo-Lyun Roh (E-mail: withtry@ kangwon.ac.kr)

(C2015 The Society of Physical Therapy Science. Published by IPEC Inc. This is an open-access article distributed under the terms of the Creative Commons Attribution Non-Commercial No Derivatives (by-ncnd) License $<$ http://creativecommons.org/licenses/by-nc-nd/3.0/> . ing pattern can be affected, as the center of gravity and the center of pressure shift. If balance disturbance occurs while the center of gravity is biased to one side due to the external load, the user might lose his/her balance and fall down on a sloped or an uneven surface. Therefore, using a walker is not perfectly safe due to this risk. This loss of balance could be a significant risk factor for elderly people, as they are exposed to increased risk of damage or fall ${ }^{4)}$. In this study, we examine elderly people's walker-aided walking with different locations and weights of the walker pocket to provide information on safe walker-aided walking.

\section{SUBJECTS AND METHODS}

The subjects were 20 elderly men (mean age: $75.67 \pm 4.27$ years, mean height: $163.67 \pm 5.53 \mathrm{~cm}$, mean weight: $61.08 \pm 7.38 \mathrm{~kg}$ ) who lived in Kangwon-do, Korea. The inclusion criteria for the subjects were right-handedness, and no neurologic or orthopedic problems that could hinder walking, and no visual impairment ${ }^{5)}$. All the subjects received sufficient explanation about the objectives of the study before the experiment and provided their consent to participation. This study was reviewed and approved by the Kangwon National University Institutional Review Board. All the subjects signed an informed consent form.

First, the physical properties of the subjects were 


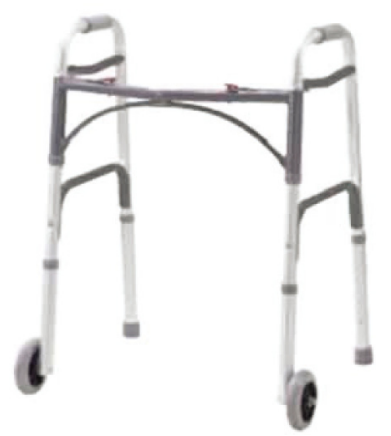

Fig. 1. Walker-aid

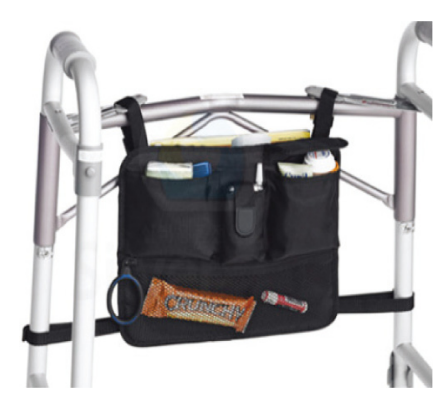

Fig. 2. Walker pocket

cessed using SPSS 20.0 for the statistical treatment of the data. Descriptive statistics were used for the general characteristics of the subjects. Two-way ANOVA was conducted to examine the differences among the three groups, depending on the location and weight of the walker pocket. The significance level was chosen as 0.05 .

Before the experiment, the subjects performed sufficien stretching and a three-minute walking exercise with a walker to familiarize themselves with walking with the walker. The experiment began when the subjects could maintain natural walking. They started walking $30 \mathrm{~cm}$ before the start point of the walking analyzer. In this study, the WalkWay MG-1000 (Animaco, Japan) walking analyzer was used to measure the step length, stride, step width, and time according to the weight and location of the walking aid pocket. Moreover, a front-wheeled walker with non-skid tips on the back legs was used, and it could be pushed and moved forward by lifting the two back legs (Figs 1,2).

In general, a walker handle should be located at the ulnar styloid when the user is in a standing position, with the arms relaxed and the elbow joint flexion at $15^{\circ}$ to $20^{\circ}$. The walker is supposed to equal the height of the greater trochanter of the femur ${ }^{6}$. However, a walker height one inch greater than the height of the greater trochanter of the femur has been reported to be more efficient in terms of gait speed, plantar prints on the paralyzed side, forward shift of the body's center, and contact area of the heel ${ }^{7}$. In this study, the femur height of the subjects was measured, and the handle height was adjusted to one inch above it, with the elbow joint flexion angle set to $15^{\circ}$ to $20^{\circ}$, similar to the conditions reported by $\mathrm{Cha}^{7}$.

The walker pocket was a commercially sold fabric pocket made to hold personal belongings, such as glasses, notes, medicine, and mobile phone. It had dimensions of $29.8 \mathrm{~cm}$ $\times 27.3 \mathrm{~cm} \times 2.5 \mathrm{~cm}$ and a weight of $454 \mathrm{~g}$. To examine the effect of weight change on walking with the walking aid pocket in different locations, the pocket was attached to the left, center, and right sides of the walker, and the weight was altered in each case.

With reference to McGibbon, Kerbs, and Mann ${ }^{8}$, the subjects were divided into three groups different pocket weights relative to the average weight of the group: $0 \%$ (no pocket), $2.5 \%$, and $5.5 \%$. Specifically, the first group used a walker without a pocket, the second group used a walker with a $2 \mathrm{~kg}$ pocket (average weight $61.08 \mathrm{~kg} \times 2.5 \%+$ pocket weight $454 \mathrm{~g}$ ), and the third group used a walker with a $4 \mathrm{~kg}$ pocket $(61.08 \mathrm{~kg} \times 5.5 \%+$ pocket weight $454 \mathrm{~g})$.

Data for each item from the walking analysis were pro-

\section{RESULTS}

Two-way ANOVA was conducted to examine the changes in the subjects' walking, depending on the location and weight of the pocket. For all the measured characteristics of walking, no correlation was found between the weight and the location of the walker pocket. Step width showed a statistically significant difference in the location of the pocket $(\mathrm{p}<0.01$, Table 3$)$, while no statistically significant difference was observed in all the other walking characteristics. Step width was the narrowest when the pocket was attached to the right side and the widest when attached to the left side. That is, walking stability was the greatest when the pocket was attached to the right side.

Statistically significant differences were found in step length, step width, stride, and time among different pocket weights $(p<0.001$, Tables $1,2,4 ; p<0.01$, Table 3$)$. The heavier the pocket was, the shorter the step length and the stride, the greater the step width, and the longer the time. In other words, as the pocket grew heavier, the subjects walked slower and with less stability.

\section{DISCUSSION}

This study examined the changes in walker-aided walking of elderly people elicited by different weights and locations of the walker pocket. The results show that step width was the narrowest and walking stability was the greatest when the walker pocket was attached to the right side of the walker. When the pocket was heavier, the gait speed and walking stability decreased. Walking stability was higher when the walker pocket was attached to the right side, presumably because all the subjects were right-handed, and their right limbs were accordingly dominant.

Generally, the use of a walker enhances walking efficiency by distributing the body weight to an aid device; thus, reducing the load on the muscles and joints of the lower limbs ${ }^{9}$. However, an increased external load causes increased energy consumption and decreased step length and 
Table 1. Step length according to the weight and the location of the walker pocket

\begin{tabular}{cccc}
\hline \multirow{2}{*}{ Weight*** } & \multicolumn{3}{c}{ Position } \\
\cline { 2 - 4 } & Lt. & Rt. & Mid. \\
\hline $0 \mathrm{~kg}^{\mathrm{a}}$ & $41.34 \pm 10.85$ & $47.64 \pm 8.39$ & $44.50 \pm 8.98$ \\
$2 \mathrm{~kg}^{\mathrm{b}}$ & $34.11 \pm 9.29$ & $38.58 \pm 8.09$ & $36.84 \pm 8.13$ \\
$4 \mathrm{~kg}^{\mathrm{c}}$ & $30.37 \pm 10.08$ & $35.00 \pm 8.71$ & $33.69 \pm 9.18$ \\
Post hoc & & $\mathrm{c}, \mathrm{b}>\mathrm{a}$ & \\
\hline$* * * \mathrm{p}<0.001$ & & &
\end{tabular}

Table 3. Step width according to the weight and the location of the walker pocket

\begin{tabular}{cccc}
\hline \multirow{2}{*}{ Weight** } & \multicolumn{3}{c}{ Position** $^{*}$} \\
\cline { 2 - 4 } & Lt. $^{1}$ & Rt. $^{2}$ & Mid. $^{3}$ \\
\hline $0 \mathrm{~kg}^{\mathrm{a}}$ & $11.78 \pm 4.12$ & $8.60 \pm 4.02$ & $10.19 \pm 4.00$ \\
$2 \mathrm{~kg}^{\mathrm{b}}$ & $14.15 \pm 5.33$ & $10.78 \pm 3.07$ & $12.46 \pm 3.18$ \\
$4 \mathrm{~kg}^{\mathrm{c}}$ & $17.50 \pm 7.29$ & $12.29 \pm 4.08$ & $14.90 \pm 4.15$ \\
Post hoc & & a,b $>$ b,c $; 3,2>2,1$ \\
\hline$* * \mathrm{p}<0.01$ & &
\end{tabular}

stride that could reduce gait speed. Lee et al. reported that walker-dependent subjects showed a slower gait speed than a group of healthy people and elderly people with pain in the $\mathrm{knee}^{10)}$. However, Wang et al. reported that elderly people who use a three-wheeled walker did not show a difference in gait speed and step length compared with young people ${ }^{2)}$. The conflicting results of earlier studies on the use of walking aid devices may be due to the different types of walkers used. Daisuke Fujita et al. ${ }^{11)}$ compared the walking of people who used a rollator with forearm support and those who used a rollator with a handgrip and cart. They found that the gait speed was greater for people who used a rollator with forearm support and that changes in walking characteristics were observed for different types of walking aid devices.

In this study, the most popular front-wheeled walker in Korea was used, and the focus was placed on the walker pocket. The results show that the pocket weight had a significant influence on the walker-aided walking of elderly people. A heavier pocket slowed down the gait speed, impeding the movements of the elderly subjects. When the pocket weight was $5.5 \%$ or more of the user's weight, the gait speed slowed down by about a third, compared to the case of when a walker without a pocket was used. Walking fast with a walker that has a heavy pocket seems to cause accidents, such as a fall. Moreover, attaching the pocket to the right side of the walker seemed to improve walking stability. Therefore, our recommendation is that the pocket should be attached to the right side of the walker and that the pocket weight should be kept under $5.5 \%$ of the user's weight when elderly people use a walker with a pocket. This study is limited by the fact that it did not provide information on the results of falling accidents in relation to the location and weight of the pocket. Follow-up studies should to be conducted to address this issue.
Table 2. Stride according to the weight and the location of the walker pocket

\begin{tabular}{cccc}
\hline \multirow{2}{*}{ Weight*** } & \multicolumn{3}{c}{ Position } \\
\cline { 2 - 4 } & Lt. & Rt. & Mid. \\
\hline $0 \mathrm{~kg}^{\mathrm{a}}$ & $85.28 \pm 19.46$ & $91.60 \pm 18.78$ & $88.44 \pm 18.64$ \\
$2 \mathrm{~kg}^{\mathrm{b}}$ & $72.61 \pm 19.93$ & $77.63 \pm 19.33$ & $67.53 \pm 22.08$ \\
$4 \mathrm{~kg}^{\mathrm{c}}$ & $58.46 \pm 23.99$ & $66.74 \pm 21.94$ & $62.61 \pm 22.71$ \\
Post hoc & & $\mathrm{c}, \mathrm{b}>\mathrm{a}$ & \\
\hline$* * * \mathrm{p}<0.001$ & & &
\end{tabular}

Table 4. Walking time according to the weight and the location of the walker pocket

\begin{tabular}{|c|c|c|c|}
\hline \multirow{2}{*}{ Weight**** } & \multicolumn{3}{|c|}{ Position } \\
\hline & Lt. & Rt. & Mid \\
\hline $0 \mathrm{~kg}^{\mathrm{a}}$ & $1.80 \pm 0.56$ & $1.49 \pm 0.43$ & $1.64 \pm 0.47$ \\
\hline $2 \mathrm{~kg}^{\mathrm{b}}$ & $3.86 \pm 0.54$ & $3.59 \pm 0.76$ & $3.73 \pm 0.62$ \\
\hline $4 \mathrm{~kg}^{\mathrm{c}}$ & $4.38 \pm 0.78$ & $4.14 \pm 0.88$ & $4.26 \pm 0.83$ \\
\hline Post hoc & & $a>b>c$ & \\
\hline
\end{tabular}

\section{REFERENCES}

1) Choi DS: A study on the usability of the walking aids - focus on physically disabled elderlies. Bull Kore Socie Basic Des Art, 2007, 8: 623-629.

2) Wang T, Merlet JP, Sacco G, et al.: Walking analysis of young and elderly people by using an intelligent walker ANG. Robot Auton Syst, 2014, -.: 16.

3) Jung KT, Shin DJ, Chun KJ, et al.: Anthropometric analysis and usability evaluation of four-wheeled walker. J Ergon Socie Kore, 2009, 28: 17-26. [CrossRef]

4) Park YH, Kim YK, Song WK et al.: The effect of using the walker on the kinematics and muscle activation pattern during gait and sit-to-stance in normal elderly. Kore HIC confer, 2011, 1: 293-295.

5) Kim JS, Kim K, Jun DH: The effect of changes in young women's static balance after performing walking task with different carrying bag positions. J Kore Socie Physi Med, 2011, 6: 51-58.

6) Lee YR: Effect of the height of Walker on muscle activity in elbow extensor and energy expenditure index during ambulation with walker. Hanseo university master's thesis, 2004.

7) Cha YJ: The effect of cane height on foot pressure of affected side in adult hemiplegia. Daegu university master's thesis, 2009.

8) McGibbon CA, Kerbs DE, Mann RW: Pressure exerted on acetabular cartilage in-vivo while using a cane and carrying loads in one hand. Gait Posture, 1994, 4: 167-20.

9) Kim BK, Kim TH: The change of lower-limb muscle activity according to gait speed when normal and assistive gait of older. Kore J Orthope Man Physi Ther, 2008, 14: 60-67.

10) Lee IH, Park SY: A comparison of gait characteristics in the elderly people, people with knee pain, and people who are walker dependent people. J Phys Ther Sci, 2013, 25: 973-976. [Medline] [CrossRef]

11) Fujita D, Kobara K, Osaka H, et al.: The influence of rollators with forearm support on walking speed, endurance and dynamic balance. J Phys Ther Sci, 2012, 24: 667-670. [CrossRef] 